\title{
A pre-harvest rot of persimmon fruit caused by Phytophthora cactorum in New Zealand
}

\author{
Joy L. Tyson • Robert K. Taylor • Carol L. Curtis • \\ Michael A. Manning
}

Received: 28 October 2013 / Accepted: 18 December 2013 /Published online: 4 January 2014

(C) Australasian Plant Pathology Society Inc. 2013

\begin{abstract}
Phytophthora cactorum is reported causing a fruit rot of persimmon (Diospyros kaki) in New Zealand. The oomycete was isolated from rapidly developing brown rots of fruit that were observed pre-harvest. $P$. cactorum was identified on the basis of morphology and molecular tests, and confirmed as the causal agent by fulfilling Koch's postulates.
\end{abstract}

Keywords Persimmon · Diospyros kaki $\cdot$ Phytophthora cactorum $\cdot$ New Zealand · CARPP medium

Diospyros kaki (Japanese persimmon), a member of the Ebenaceae, was introduced into New Zealand in 1873 (Kitagawa and Glucina 1984). Persimmons are grown in the North Island of New Zealand and are of minor economic importance, with export volumes of 1,748 tonnes in 2010, 1,438 $\mathrm{t}$ in 2011 and 1,566 $\mathrm{t}$ in 2012 (NZHEA 2013).

Diseases of persimmon recorded in New Zealand include grey mould (Botrytis cinerea), bacterial blast (Pseudomonas syringae pv. syringae) and post-harvest rots caused by Penicillium spp. (Kitagawa and Glucina 1984). Other reports include Colletotrichum acutatum causing fruit rots (Lardner et al. 1999), Colletotrichum horii from anthracnose lesions on persimmon fruit and twigs (Weir and Johnston 2010), and basal root rot caused by Cylindrocladium floridanum (Boesewinkel 1986).

In June 2011, a small 'spray-free' orchard near Tauranga experienced pre-harvest rotting of 'Fuyu' persimmon fruit.

J. L. Tyson $(\varangle) \cdot$ C. L. Curtis $\cdot$ M. A. Manning

The New Zealand Institute for Plant \& Food Research Limited, Private Bag, 92169 Auckland, New Zealand

e-mail: Joy.Tyson@plantandfood.co.nz

R. K. Taylor

Plant Health and Environment Laboratory, Ministry for Primary Industries, PO Box 2095, Auckland 1140, New Zealand
The orchard was planted in 1981, mainly on D. kaki rootstock, and had previously been a dairy farm. There was no evidence of stem cankers or collar rots on the trees. However, some of the pollinators, which had Diospyros lotus as the rootstock, had previously experienced tree decline, with sparse foliage and a general 'unthriftiness'.

The fruit rots were patchy within the crown of the trees, and moved across the orchard as the season progressed, eventually becoming apparent in a neighbouring orchard. Approximately $30 \%$ of the trees were affected and few fruit could be sold. The symptoms were unlike those of other common persimmon fruit-rotting pathogens in New Zealand, such as the anthracnose caused by Colletotrichum spp., appearing before harvest and forming circular light brown rots that progressed rapidly over the fruit, along with the distinctive smell typical of Phytophthora-rotted fruit. The fruit remained attached to the tree until harvest. A white mycelial web developed over the rotten areas after harvest.

Histological examination of the fruit rots revealed large numbers of typical Phytophthora sporangia forming on the surface of the fruit. Surface-sterilised pieces of rotted tissue were placed onto a selective medium, modified from Jeffers and Martin (1986), consisting of corn meal agar amended with $2 \mathrm{mg} / \mathrm{L}$ carbendazim, $250 \mathrm{mg} / \mathrm{L}$ ampicillin, $10 \mathrm{mg} / \mathrm{L}$ rifampicin, $5 \mathrm{mg} / \mathrm{L}$ pimaricin and $100 \mathrm{mg} / \mathrm{L}$ pentachloronitrobenzene (CARPP medium). A Phytophthora species was consistently isolated after $72 \mathrm{~h}$ growth at room temperature (c. $20^{\circ} \mathrm{C}$ ).

The isolated Phytophthora was maintained on V8 juice agar (Hine and Aragaki 1963). Morphological characteristics were studied on V8 juice agar and Difco corn meal agar (CMA) after up to 7 days growth at c. $20{ }^{\circ} \mathrm{C}$ under a 12 $\mathrm{h} / 12 \mathrm{~h}$ light/dark regime. All isolates were homothallic, forming oogonia and sporangia readily on V8 juice agar (Fig. 1). Oogonia were parangynous, plerotic or aplerotic, 27.87$31.05 \mu \mathrm{m}$ diameter. Sporangia were ellipsoid/ovoid (39-48× 29-35 $\mu \mathrm{m}$ ), papillate (papilla $4 \mu \mathrm{m}$ depth, 5-7 $\mu \mathrm{m}$ width), 
caducous (pedicel $3.64 \mu \mathrm{m}$ length). No hyphal swellings or chlamydospores were observed.

The internal transcribed spacer (ITS) ribosomal DNA gene region was amplified, using primers ITS 4 and 6 (White et al. 1990), from three isolates (ICMP 20004, 20021, 20022), producing an amplicon of approximately $900 \mathrm{bp}$. The sequences of the amplified products were deposited in the GenBank database and assigned accession numbers KF785803, KF785804 and KF785805. BLASTn analysis of the ITS amplicon showed that the region was $99.9 \%$ homologous to $P$. cactorum sequences (accessions EF1932238; EF193231) in GenBank and $99 \%$ homologous to $P$. cactorum sequences (AB217671; AF266772) in the Phytophthora-ID database version 2 (Grunwald et al. 2011). Analysis of neighbour-joining trees of the ITS sequences generated in Geneious Pro 5.5.6 (Biomatters, Auckland, New Zealand) placed these isolates into the same clade as P. cactorum (Fig. 2). Other Phytophthora species recorded on persimmon such as $P$. cinnamomi and $P$. citrophthora clustered into different clades. On the basis of morphology and the molecular tests, the isolates were identified as Phytophthora cactorum. Reference cultures have been deposited in the
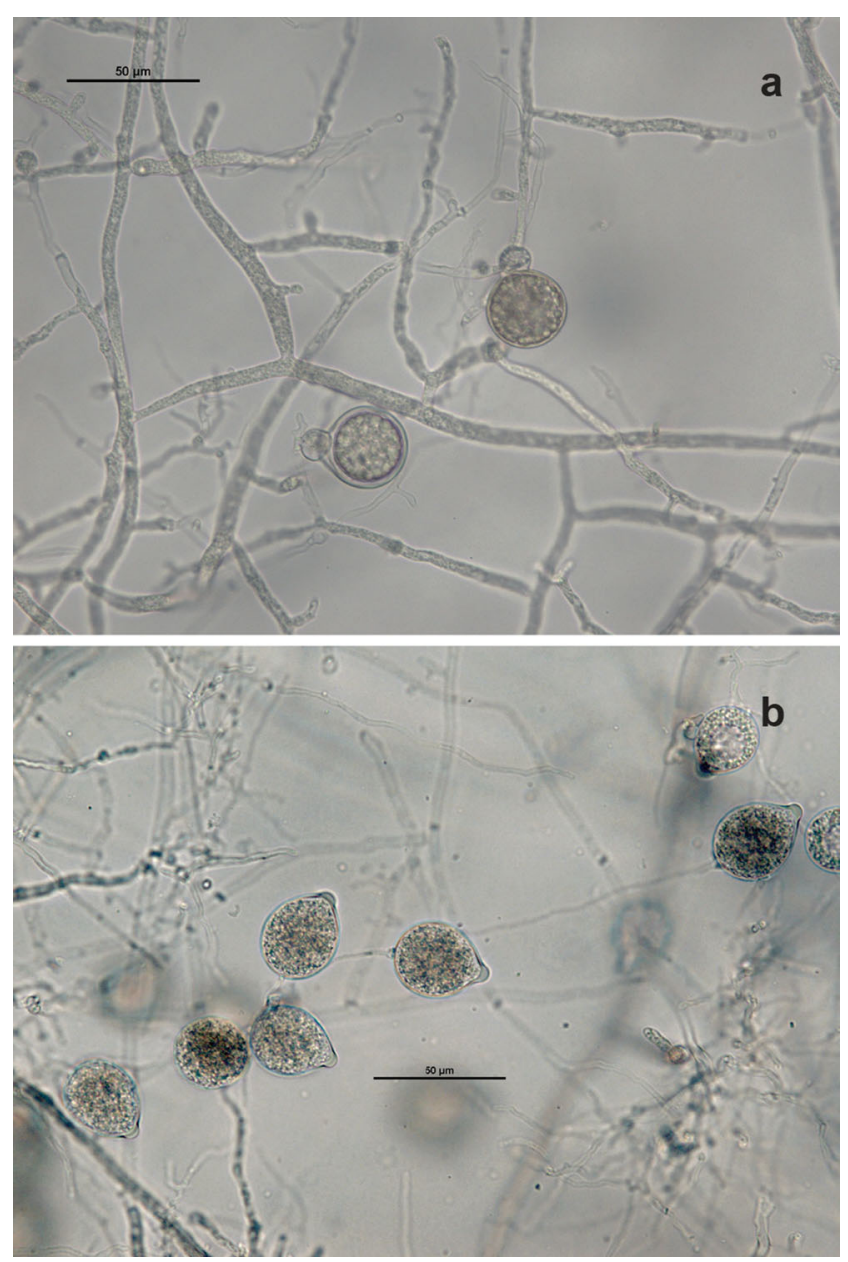

Fig. 1 a Oogonia and $\mathbf{b}$ sporangia of Phytophthora cactorum growing on clarified V8 juice agar (photographs by JL Tyson)
International Collection of Microorganisms from Plants, Landcare Research, Auckland, New Zealand (ICMP 20004, 20021, 20022).

To fulfil Koch's postulates, a sterile scalpel was used to make skin wounds in six mature persimmon fruit. A small mycelial plug of each of three isolates of $P$. cactorum from persimmon was inserted into wounds on each of two fruit. Two persimmon fruit inoculated in the same manner with sterile V8 juice agar and two wounded un-inoculated fruit served as controls. Fruit were incubated in a humid chamber at c. $20^{\circ} \mathrm{C}$ for 4 days. The inoculations were carried out three times. Brown rots similar to the initial field symptoms began to form on all the inoculated fruit within one day of inoculation and the rot rapidly progressed to cover over $50 \%$ of the fruit within 4 days (Fig. 3). No symptoms were seen on any of the control fruit. Phytophthora cactorum was re-isolated from all the inoculated fruit.

P. cactorum is polyphagous, "parasitising more than 200 plant species in 150 genera representing 60 plant families" (Erwin and Ribeiro 1996). It has a worldwide distribution and is best known for causing root, collar and crown rot diseases. Although fruit rots can be caused by $P$. cactorum, they are generally of minor economic importance and usually follow contact with soil particles that have been splashed upwards during heavy rain. In apples and pears, this results in dark brown lesions that can rapidly cover the entire fruit (Erwin and Ribeiro 1996).

The climatic conditions in the Tauranga region at the time disease symptoms were observed (June 2011) were slightly warmer (May $15.1{ }^{\circ} \mathrm{C}$ and June $12.6{ }^{\circ} \mathrm{C}$ ) and substantially

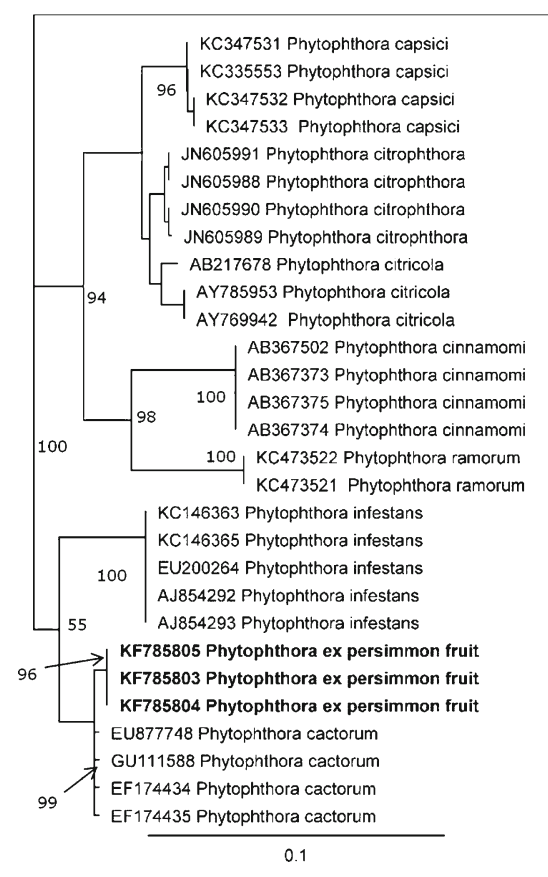

Fig. 2 Neighbour joining tree generated from ITS gene sequences of Phytophthora species. Bootstrap values from 1,000 replicates are shown at each node 


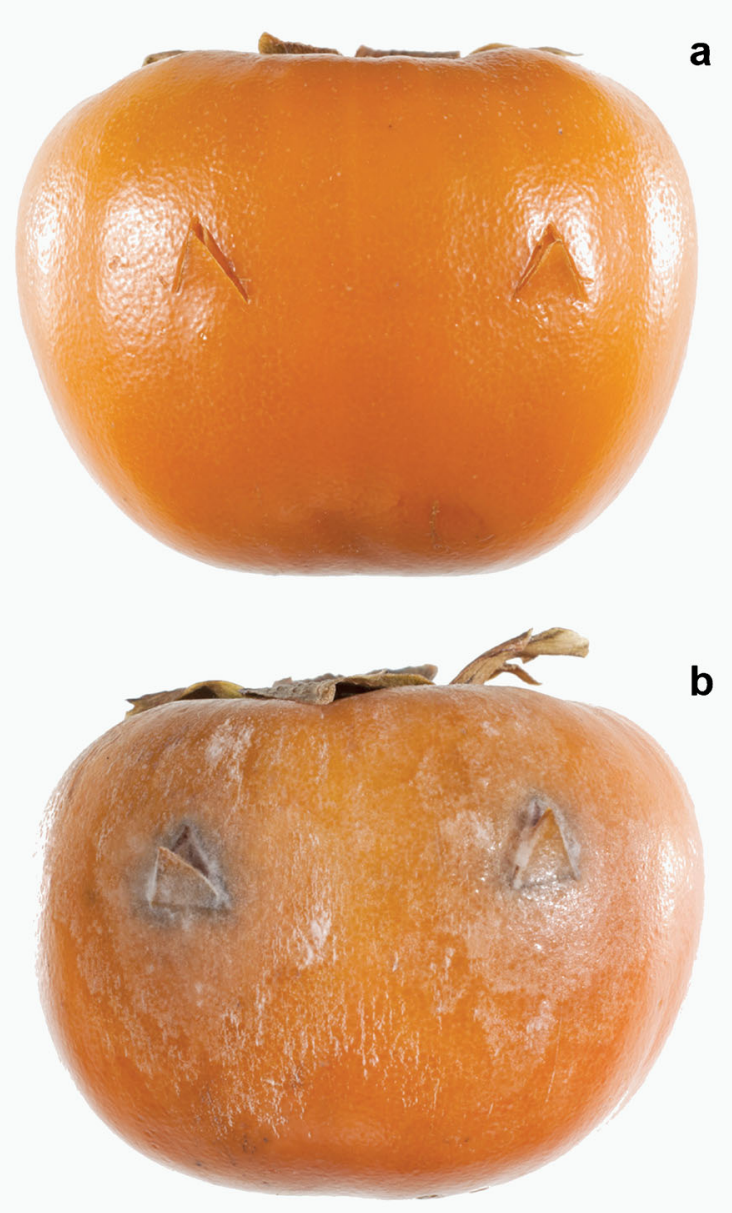

Fig. 3 Symptoms on persimmon a control fruit and $\mathbf{b}$ fruit 4 days after wound-inoculation with Phytophthora cactorum (photographs by Tim Holmes, Plant \& Food Research)

wetter (May $173.2 \mathrm{~mm}$ and June $160.8 \mathrm{~mm}$ ) than the 20-year average for these months. These conditions were probably ideal for Phytophthora spp. to be splashed from the soil onto fruit and to cause disease. There is anecdotal evidence that this type of fruit rot was also a problem in 2010 . There were very few fruit rots of this type in 2012 and none observed in 2013.

Previous reports of Phytophthora spp. on persimmon in New Zealand consist of a brief note of Phytophthora sp. on D. kaki (Dingley 1969), and a report of Phytophthora sp. causing a basal rot on D. kaki in Hamilton in 1980 (Boesewinkel 1982). The Plant Pest Information Network database (PPIN 2013) records $P$. cinnamomi on roots, and P. citricola on roots and seedlings.

Worldwide, $P$. cinnamomi has been implicated in tree death of D. pentamera in Australia (Brown 1976); P. capsici has been recorded on $D$. kaki in Italy; $P$. citrophthora has been recorded on D. kaki in Iran; and Phytophthora sp. has been recorded on Diospyros spp. in Australia, Japan and the USA (Farr and Rossman 2013). Phytophthora diospyri is recorded on persimmon in the former USSR (Mkervali 1990), but no further information was found on this species.
Smith (1937) described artificial inoculations of $P$. cactorum on stems of various plants, including D. kaki. He found that in one of five plants inoculated, a 5-mm lesion had developed after 90 days.

To the authors' knowledge, this is the first report of Phytophthora cactorum affecting persimmon in New Zealand, and the first record of $P$. cactorum causing a fruit rot of persimmon worldwide. It is also likely to be the first report of natural infection of Diospyros kaki by Phytophthora cactorum.

\section{References}

Boesewinkel HJ (1982) A list of 142 new plant disease recordings from New Zealand and short notes on three diseases. Australas Plant Pathol 11:40-43

Boesewinkel HJ (1986) New plant disease records from New Zealand. Australas Plant Pathol 15(1):18-21

Brown BN (1976) Phytophthora cinnamomi associated with patch death in tropical rain forests in Queensland. APPS Newsletter 5(1):1-4

Dingley JM (1969) Records of plant diseases in New Zealand. Bulletin of the New Zealand Department of Scientific and Industrial Research, vol. 192. Department of Scientific and Industrial Research, Wellington, New Zealand

Erwin DC, Ribeiro OK (1996) Phytophthora dieases worldwide. The American Phytopathological Society, St Paul, Minnesota, USA

Farr DF, Rossman AY (2013) Fungal Databases, Systematic Mycology and Microbiology Laboratory, ARS, USDA. http://nt.ars-grin.gov/ fungaldatabases/. Accessed October 30, 2013

Grunwald NJ, Martin FN, Larsen MM, Sullivan CM, Press CM, Coffey MD, Hansen EM, Parke JL (2011) Phytophthora-ID.org: a sequencebased Phytophthora identification tool. Plant Dis 95(3):337-342

Hine RB, Aragaki M (1963) Pathogenicity, vitamin nutrition and cultural characteristics of isolates of Phytophthora parasitica from carnation and other hosts in Hawaii. Phytopathology 53:1194-1197

Jeffers SN, Martin SB (1986) Comparison of two media selective for Phytophthora and Pythium species. Plant Dis 90:1038-1043

Kitagawa H, Glucina PG (1984) Persimmon culture in New Zealand. DSIR Information Series No. 159. New Zealand Department of Scientific and Agricultural Research, Wellington, New Zealand

Lardner R, Johnston PR, Plummer KM, Pearson MN (1999) Morphological and molecular analysis of Colletotrichum acutatum sensu lato. Mycol Res 103(3):275-285

Mkervali VG (1990) Harmfulness of diseases infecting subtropical plants. Subtropicheskie Kul'tury 1:126-131

NZHEA (2013) Persimmons. New Zealand Horticulture Export Authority. http://www.hea.co.nz/index.php/2012-05-11-03-05-28/ persimmon-trade. Accessed 1 October 2013

PPIN (2013) Ministry for Primary Industries, New Zealand. http://www. mpi.govt.nz/biosecurity-animal-welfare/pests-diseases/ppin. Accessed 25 October 2013

Smith CO (1937) Inoculation of some economic plants with Phytophthora cactorum and P. citrophthora. Phytopathology 27:1106-1109

Weir BS, Johnston PR (2010) Characterisation and neotypification of Gloeosporium kaki Hori as Colletotrichum horii nom. nov. Mycotaxon 111:209-219

White TJ, Bruns T, Lee S, Taylor J (1990) Amplification and direct sequencing of fungal ribosomal RNA genes for phylogenetics. In: Innis MA, Gelfand DH, Sninsky JJ, White TJ (eds) PCR Protocols: A Guide to Methods and Applications. Academic Press, Inc., New York, pp 315-322 